\title{
Synbiotic and antioxidant activity of fruit by-products and their effect on human health
}

\author{
Akter, B. and *Rabeta, M.S. \\ School of Industrial Technology, Food Technology Division, Universiti Sains Malaysia, 11800 Minden, \\ Penang, Malaysia.
}

\author{
Article history: \\ Received: 27 July 2020 \\ Received in revised form: 9 \\ August 2020 \\ Accepted: 27 August 2020 \\ Available Online: 2 \\ September 2020
}

\section{Keywords:}

Antioxidant,

By-product,

Prebiotic,

Probiotic,

Synbiotic,

Therapeutic

DOI:

https://doi.org/10.26656/fr.2017.5(1).401

\begin{abstract}
Food supplements are extensively used as a natural remedy to improve human health condition. Considerable progress has been reported recently by several studies to analyse the bioactive substances and their functional activities of fruit by-product. The food industry generates a vast amount of wastes during manufacturing or processing, which are mainly skins, kernels, and seeds. These by-products contain valuable bioactive compounds such as antioxidants, vitamins, minerals, and indigestible food ingredients called prebiotics. Peels from fruits like yellow rambutan, green kiwi, mango, and papaya exhibit a strong anti-proliferative, anti-cardiovascular, anti-oxidant, and hepatoprotective effects due to the presence of bioactive compounds namely flavonoid, B-type catechin dimer, and penta-O-galloyl-glucoside. This review will illustrate a new concept of functional foods by providing information on alternative sources of bioactive compounds from food by-product and their efficacy in human nutrition. This study will also recapitulate the presence of bioactive components in fruit by-product, their way of action, constitution, health benefits, and probable therapeutic action in the treatment of disease prevention.
\end{abstract}

\section{Introduction}

The most commonly used horticultural crops are fruits and vegetables among other goods which can consume as fresh, processed, or minimally processed form because of their nutritious components. Due to the changing pattern of diet and increasing population, consumer demand for fruits and vegetables has increased drastically (Sagar et al., 2018). However, Irfanoglu et al. (2014), have reckoned that around one-third of the human food is wasted or lost worldwide, which is near to 1.3 billion tons of food each year. Actually, losses and wastage are high (reaching up to $60 \%$ ) in fruit and vegetable processing, which become a critical issue for human nutrition and habitat (Sagar et al., 2018). Only a small quantity of these is utilised as fertiliser and pet food (Hernández-Alcántara et al., 2016). Moreover, these by-product losses are not only the losses of food products, but also represent the losses of other assets, i.e., energy, field, water, compost chemicals, and manpower (Sagar et al., 2018).

Studies have reported that the skin part of grapes and bananas; and seeds of mangoes and jackfruits comprise of high phenolic concentrations, which is $15 \%$ higher than the amount in fruit pulp (Sagar et al., 2018). Phytochemical information provides the basis for developing new functional beverages and foods (Ibrahim et al., 2017). Fruits waste can be used to extract and isolate potential prebiotics and probiotics that can be the cheapest source for food, textile, and pharmaceutical industries. Therefore, the appropriate utilisation of waste materials attained from the food industry can be a new initiative towards sustainable development to alleviate environmental pollution and to improve health by adding the health-improving elements such as dietary fibres, phenols, vitamins, carotenoids, and others (Sagar et al., 2018). According to the study of Wadhwa (2016), fruit by-product is rich in antioxidants and other bioactive compounds that protect human health from several degenerative diseases. It is reported that the phenolic compounds and other antioxidants in fruit by-product exhibit anti-microbial, anti-cancer and anti-oxidative effects; reduce the risk of cardiovascular diseases, capillary fragility, plasma cholesterol level, and inhibit platelet aggregation (Wadhwa, 2016). Yellow rambutan (Nephelium lappaceum) peel extract exhibits a strong 
anti-proliferative activity in osteosarcoma and breast cancer cells and also reduces the proliferation of colon tumour cells because of the presence of the flavonoid compound (Khaizill et al., 2013). Green kiwi peels can be utilised as a source of natural functionalizing ingredients with several health benefits that contain higher phenolic content particularly B-type catechin dimer and showed cytotoxicity and anti-inflammatory activity (Dias et al., 2020). Studies have indicated that mango peel and seed kernel extract contain penta-Ogalloyl-glucoside, which exhibits several bioactivities including anti-cardiovascular, anti-oxidant, anti-tumour, and hepatoprotective effects (Wadhwa, 2016). This review aims to briefly discuss the availability of bioactive compounds in fruit by-product, their mechanisms of action, and the current insights into their therapeutic potential for preventing chronic diseases. Although several studies have shown the beneficial effects of such compounds on human health, further research should be conducted on the acquisition of new strains to produce synbiotics, clinical trials, and safety of use to achieve accurate evidence.

\section{The extent of fruit by-product}

The unconsumed parts of fruit and vegetables are known as by-products which are simply discarded for multiple reasons, i.e., inadequate handling operations and morphological characteristics of the product. However, the quantity of fruit waste changes based on product and morphological materials, including peels, pulp, seeds, kernel, pomace, and roots (Sagar et al., 2018). With respect to the literature review, apples can produce $10.91 \%$ by-product from seeds and $89.9 \%$ pulp as an end product during cutting. Papaya generates around $8.5 \%$, $6.5 \%, 32 \%$ and $53 \%$ of peel residue, seeds, the pulp (not usable), and finished product during dicing, respectively. During peeling, mandarins yield $16 \%$ of peels and $84 \%$ of the final product. The processing of pineapple generates approximately $14 \%, 9 \%, 15 \%, 15 \%$ and $48 \%$ of peels, core, pulp, top and finished product, respectively. Mango processing yields around $11 \%$ of peels, $13.5 \%$ of seeds, $18 \%$ of the core, and $58 \%$ of the final product (Joshi et al., 2012; Sagar et al., 2018). Furthermore, fruits and vegetables yield about 5.5 million metric tons (MMT) of by-product including pomace. During processing grape and wine, the industry can produce approximately 5 - 9 MMT of solid waste per year globally, in which $20 \%-30 \%$ are processed materials. Canning and frozen processing yields around 6 MMT of residue from fruits and vegetables yearly, which consist of $20 \%-30 \%$ leaves, petioles, and stems of broccoli or carrot (Sagar et al., 2018).

\section{Major bioactive component sources}

Biologically active compounds and phenolic components are present in peels, seeds, and pomace of fruits. Mostly, apples, pears, banana, dragon fruit, berries, and mangoes are considerably higher than those found in their edible parts (Wadhwa, 2016). This finding suggested that these wastes have the potential for isolating bioactive compounds. Table 1 represents the applications of food by-product as sustainable ingredients. Studies have shown that the pomace of orange, raspberry, pear, watermelon, peach, banana, apple, cherry, durian seeds, date pits and mango peels are used as functional ingredients in processed food because of their pectin carotenoids and bound antioxidant contents (Wadhwa, 2016). According to HernándezAlcántara et al. (2016), fruit (e.g., banana, apple) peels and carrot pulp residue have been found to be good sources of fibre and antioxidants which functioning as prebiotics for the growth of lactic acid bacteria. Table 2 shows the amount of edible part and the by-product of different fruits produced during processing in the food industry (Goni and Hervert-Hernandez, 2012; Barbulova et al., 2015). Pineapple by-product can be utilised as alternative cheapest source for probiotic cultivation in comparison to expensive MRS (De Man, Rogosa and Sharpe agar) medium. Moreover, after fermentation, these waste recoveries can develop the overall economic processing unit in a country (Pyar et al., 2014).

\subsection{Watermelon peel}

Malaysia's watermelon production in 2017 was 172,275.36 metric tons (Department of Agriculture of Malaysia, 2017). Watermelon has potential therapeutic effects, which can be attributed to its antioxidant activity (Koocheki et al., 2007). Particularly, the antioxidant properties of citrulline in watermelon rind helps to protect humans from free radical damage. Moreover, citrulline can be converted into a type of amino acid known as arginine, which plays a significant role in the immune and circulatory systems and the human heart (Rimando and Perkins-Veazie, 2005). Watermelon rind is believed to have the ability to relax blood vessels, and work for cancer, cardiovascular diseases, apart from addressing erectile function (Ibrahim et al., 2017). Recent studies have found that watermelon rind powder has been used to prepare cake batter for bakery products by mixing with flour (Al-Sayed and Ahmed, 2013).

\subsection{Grape peels and seeds}

According to Food and Agriculture Organization (FAO) (2010), the world total grape production is 67116255 tons, and China is the top grape-producing (8651831 tons) country all over the world (Ministry of 
Table 1. Applications of food by-products as sustainable ingredients

\begin{tabular}{|c|c|c|c|c|}
\hline Byproduct & Dose & Function & Bioactive compounds & References \\
\hline Chestnut waste flour & $2 \%$ & Promote health & $\begin{array}{c}\text { Source of phenolic compound } \\
\text { and probiotic }\end{array}$ & Ozcan et al. (2016) \\
\hline Apple pulp residue & $2.5-10 \%$ & Promote health & Source of fibre & Issar et al. (2016) \\
\hline Peel of banana & $1 \%$ & Promote health & Source of fiber and probiotic & $\begin{array}{l}\text { do Espírito Santo et al. } \\
\text { (2012) }\end{array}$ \\
\hline $\begin{array}{l}\text { Powder made by } \\
\text { pineapple peel }\end{array}$ & $1 \%$ & Promote health & Act as probiotic & $\begin{array}{l}\text { Iriondo-Dehond et al. } \\
\text { (2018) }\end{array}$ \\
\hline Peel of Passion fruit & $0.70 \%$ & Promote health & Rich source of fibre & $\begin{array}{l}\text { do Espírito Santo et al. } \\
\text { (2012) }\end{array}$ \\
\hline Grape refuse flour & 10,20 , and $50 \mathrm{~g} / \mathrm{L}$ & Promote health & $\begin{array}{c}\text { Source of phenolic compound } \\
\text { and probiotic }\end{array}$ & Frumento et al. (2013) \\
\hline $\begin{array}{l}\text { Seed from pomegranate } \\
\text { fruit }\end{array}$ & $25 \mathrm{mg} / \mathrm{L}$ & $\begin{array}{l}\text { Technological } \\
\text { benefit }\end{array}$ & Source of antioxidant & $\begin{array}{l}\text { Iriondo-Dehond et al. } \\
\qquad(2018)\end{array}$ \\
\hline Grape peel flour & $0.167-1 \mathrm{~g} / 100 \mathrm{~g}$ & Promote health & Source of polyphenol & Karnopp et al. (2017) \\
\hline Grapeseed & $25 \mathrm{mg} / \mathrm{L}$ & $\begin{array}{l}\text { Technological } \\
\text { benefit }\end{array}$ & $\begin{array}{l}\text { Source of antioxidant } \\
\text { antimicrobial activities }\end{array}$ & $\begin{array}{l}\text { Iriondo-Dehond et al. } \\
\text { (2018) }\end{array}$ \\
\hline Date waste & $\begin{array}{c}0.5,1, \text { and } 2 \text { ratios of dry } \\
\text { powder/date syrup }\end{array}$ & $\begin{array}{c}\text { Technological and } \\
\text { health-promoting } \\
\text { benefit }\end{array}$ & Source of phenolic compound & Jridi et al. (2015) \\
\hline Almond skin & 100 to $400 \mathrm{mg} / \mathrm{L}$ & $\begin{array}{l}\text { Technological } \\
\text { benefit }\end{array}$ & Source of antioxidant & Nadeem et al. (2014) \\
\hline Pomegranate skin & $100 \mathrm{ml} / 25 \mathrm{~g}$ & $\begin{array}{c}\text { Technological } \\
\text { benefit }\end{array}$ & $\begin{array}{l}\text { Antioxidant and antimicrobial } \\
\text { activities }\end{array}$ & Shan et al. (2011) \\
\hline
\end{tabular}

Table 2. Quantities of some fruit by-product produced in food processing industries

\begin{tabular}{ccc}
\hline Sources & By-Products & Edible Part \\
\hline Apple & Pulp, seed core (11\%) & $89 \%$ \\
Banana & Peel (above 30\%) & $70 \%$ \\
Mandarin & Peels (16\%) & $84 \%$ \\
Mango & Seeds, peels, unusable pulp (42\%) & $58 \%$ \\
Citrus fruits & Peel (66\%) & $44 \%$ \\
Papaya & Seeds, peels, unusable pulp (47\%) & $53 \%$ \\
Passion fruit & Rind, seeds (75\%) & $25 \%$ \\
Pineapple & Core, peels, upper part, pulp (52\%) & $48 \%$ \\
Jackfruit & Peel, Seeds (50\%-70\%) & $30 \%-50 \%$ \\
Grapes & Peel, seeds, stalk (20\%) & $80 \%$ \\
Durian & Skin, seeds (60\% -70\%) & $30 \%-40 \%$ \\
Dragon fruit & Skin, seeds (30\% -45\%) & $55 \%-70 \%$ \\
\hline
\end{tabular}

Source: Goni and Hervert-Hernandez (2012); Barbulova et al. (2015); Sagar et al. (2018)

Commerce and Industry Government of India. 2011). Grape peels and seeds contain antioxidants especially phenolic components, for example, gallic acid, cyanidin3 -glucoside, epicatechin, catechin gallate, and resveratrol which contribute to reducing oxidative and free radical activities. Therefore, grape wastes can be an alternative natural source of bioactive components and can be used to develop new value-added functional food and pharmaceuticals drug.

\subsection{Pineapple waste}

In Malaysia, pineapple uses $6.3 \%$ agro-food area with an approximate production of 340,721.95 metric tons (Department of Agriculture of Malaysia, 2017). Pineapple by-product shows prebiotic characteristics which can be applied commercially in the formulations of new functional food (Sah et al., 2016). According to Pyar et al. (2014), pineapple waste is a possible source of carbon and other nutrition for the development of lactic acid by microbial systems. During canning operation, around $30 \%$ of pineapples waste is produced which can be responsible for the hostile environment if not used properly due to low protein content, high amount of carbohydrates, and fibres (Bhargava et al., 2008; Nadzirah et al., 2013; Pyar et al., 2014). Therefore, these fruit by-product could be the cheapest alternative nutrition growth source for probiotics.

\subsection{Banana Peel}

The total production of banana in Malaysia was 350,492.59 metric tons in 2017 (Department of Agriculture of Malaysia, 2017). Research findings showed that peel and seed fractions of banana contain higher antioxidants and phenolic compounds than that of in their pulp (González-Montelongo et al., 2010). The most common antioxidant components found in the banana peel are ascorbic acid, phenolic groups, tocopherol, dopamine, beta carotene, and gallocatechol 
(Bankar et al., 2010). Moreover, as a rich source of antioxidant, banana considered the suitable candidate as a functional food as opposed to cancer and heart disease (Ibrahim et al., 2017).

\subsection{Papaya peel and seeds}

Malaysia produced 83,796.99 metric tons papaya in 2017 (Department of Agriculture of Malaysia 2017). In papaya processing, the common by-products are papaya peel and seeds which represent around 8.5 to $12 \%$ of fruit weight. These by-products are the natural source of value-added nutrients and can be utilised as new nutraceutical foods, dietary additives, and pharmaceutical products (Pathak et al., 2018). Papaya peel extracts can be used in probiotic production which represents functional effects on urogenital, digestive, and immune systems in human health and also shows a protective effect against inflammation and cardiovascular diseases (Hardia and Iqbal, 2014; Pathak et al., 2018). In a quantitative analysis, $20.23 \mathrm{mg} / \mathrm{ml}$ sugar concentration was found from papaya peel extract, and the growth of Lactobacillus in the extract was determined at optimum $\mathrm{pH}(7.0)$ and temperature $\left(37^{\circ} \mathrm{C}\right)$ with a survival rate of $2.0 \%$ in $\mathrm{NaCl}$ (Hardia and Iqbal, 2014).

\section{Antioxidants}

Synthetic antioxidants are often used in the food industry for preservation purposes for a long time. Butylated hydroxyanizole (BHA) and butylated hydroxytoluene (BHT) are mostly used antioxidant additives for the preservation purpose and stabilizing the coldness, colour, aroma, and nutritive value of food products (Wadhwa, 2016). However, it is reported that BHT can be toxic if added at higher doses (Schilderman et al., 1995). Hence, the demand for replacing synthetic antioxidants from alternative natural sources is increasing tremendously. Plant material is the popular source of antioxidants. Mainly antioxidants can be categorized into two groups concerning the mode of action (Grajek et al., 2005). Firstly, the chemical substances of antioxidants can inhibit the amplification of free radical chain by donating hydrogen compound to radicals and stabilizing the radical electrons which are relocated. Tocopherols, hydrochinons, and gallusans exhibited this type of mode of action. Secondly, a synergistic way of action is demonstrated by another group of antioxidants, including oxygen scavengers and chelators which helps to bind ions that related to free radical formation. Moreover, their function involves distributing hydrogen to phenoxy radicals for regenerating antioxidant's primary function (Grajek et al., 2005). The concentrations of phytochemicals and other phenolic compounds in different fruit peels, seeds/ stones, and pomace (citrus fruits, apples, peaches, pears, banana, pomegranate, berries, and mangoes) found to be considerably greater than their respective edible portion. The result from these findings suggested that these fruit by-products could be the prospective natural sources for separating bioactive components (Wadhwa, 2016).

\subsection{Mechanism of action of antioxidants}

Epidemiological information and some clinical trials give sufficient evidence that antioxidants play a significant role in the preclusion of cancer and cardiovascular diseases (Grajek et al., 2005). Antioxidants may act as scavengers for metal chelators and reactive oxygens to decrease oxidative damage and work as a safeguard for human cells. DNA damage is considered as the principal reason for the beginning of cancerogenic aggravated by mutagenic factors like free radicals which control the cell growth, separation, and combine the signal of extracellular and intracellular cell response (Diplock et al., 1999). Based on the epidemiological study, it is revealed that higher antioxidant consumption may reduce the risk of cancer diseases impressively. The factors involved in inhibiting cancer development are as follows: $\beta$-carotene, resveratrol, curcumin, gallusan, epigallocatechine, and gingerol (Shklar, 1998). The progression of the remaining tumours is also remarkably suppressed by antioxidants. Nowadays, three principle mechanisms are considered to be responsible for the destruction and inhibition. Firstly, improving the immunological function that helps in proper identification and demolition of the cancer-causing cells in the organism. The killing factors involving tumours necrosis factor $\alpha$ (TNF- $\alpha$ ) are produced by macrophages and $\beta$ tumour necrosis factor $\beta$ (TNF- $\beta$ ) generated by lymphocytes. Antioxidants namely $\alpha$-tocopherol and $\beta$-carotene exhibited higher cytotoxic cells production which increases the cytokine production and assists in cancer cell migration leading to the destruction of a tumour's rapid growth. Secondly, mechanism of tumour destruction is associated with genetic characteristic where the antioxidants contribute in increasing p53 (wild type) gene expression whose product can provoke in protein inhabitation and reduce the expression of p53 mutants which act as oncogenes (Grajek et al., 2005).

\subsection{Potential preventive and therapeutic role of antioxidants}

Antioxidants from fruit by-product exhibited therapeutic effects in opposition to cancer, oxidative stress, immunity problem, and microorganism that can cause disease including the reduction of cardiovascular diseases, capillary fragility, platelet aggregation, and so 
on (Rice-Evans, 2001). Particularly, the extract of fruit by-product (e.g., apple peel, rambutan peel, and date pit) contains phenolic compounds and flavonoids which can actively suppress the rapid growth of tumour cells (Wadhwa, 2016). Phenolic compound and flavonoids from apple peel extract sharply inhibited the rapid growth of tumour cells in the colon, date pit extract helps to deteriorate cytotoxicity of azoxymethane that induced colonic cancer (Wadhwa, 2016). Peel extract of yellow rambutan (Nephelium lappaceum) demonstrated antiproliferative action against breast and osteosarcoma cancer (Emylia et al., 2013). The extract of mango peel and seed kernel is widely used in pharmaceutical industries. (Jahurul et al., 2015). These extracts contain penta-O-galloyl-glucoside (PGG) which possesses potential hydroxyl radicals and oxygen scavenging function; moreover, studies have revealed that PGG expressed multiple bioactivities involving beneficial effects towards the tumour, oxidative stress, and cardiovascular disease (Park et al., 2008). Particular components from passion fruit skin demonstrated a strong bronchodilator effect by relieving bronchospasm in patients with asthma. Moreover, peel extract of purple passion fruit is considered to decrease the breathing difficulties in asthma patients especially adults during their oral administration (Wadhwa, 2016).

\section{Synbiotics}

A new concept has been introduced in biogenic known as synbiotics which is composed of probiotics and prebiotics. The dietary intervention with synbiotics aimed at correcting the breakdown of gut microbiota or subsequent imbalanced diets which may offer benefits for health by simplifying the weight reduction process (Sergeev et al., 2020). Probiotics like Lactobacilli, Bifidobacterium, Saccharomyces boulardii and prebiotics such as galactooligosaccharides (GOS), xylooligosaccharides (XOS), fructo-oligosaccharides (FOS) and inulin are the most commonly used substances to produce synbiotics (Hernández-Alcántara et al., 2016). The study revealed that synbiotic supplementation along with low-calorie diet programs exhibits salutary effects on the congelation of serum irritant markers and on excess fluid volume in breast cancer with lymphedema (Vafa et al., 2020). The therapeutic potential of synbiotics includes antimicrobial and anticarcinogenic activity, antidiarrheal characteristics, defensive mechanisms against allergy, osteoporosis supersession, and immune system modulation (Manigandan et al., 2012). Figure 1 illustrates the synbiotic applications with their mode of action (George Kerry et al., 2018). Prebiotics and probiotic bacteria may impact metabolic activity on host health in diabetes by redirecting the autoimmunity, enhancing $\beta$-cell proliferation, and diminishing $\beta$-cell apoptosis (Patterson et al., 2016). Synbiotics provide a significant contribution in the metabolic output by modulating the composition in human gut microbiota which play a key role in the therapeutic application against several health diseases, ranging from infant diarrhoea to adults inflammatory disorders (Gurry, 2017). Another study reported that synbiotic bread containing Lactobacillus sporogenes and inulin showed a significant reduction in the serum lipid profile triacylglycerol (TAG), high-density lipoprotein cholesterol (HDL-C), total cholesterol (TC), and insulin levels compared to control bread (Sáez-Lara et al., 2016). The synergistic effect of synbiotic illustrated in Figure 2 which increases the growth of lactic acid to abate intestinal inflammation (Gurry, 2017).

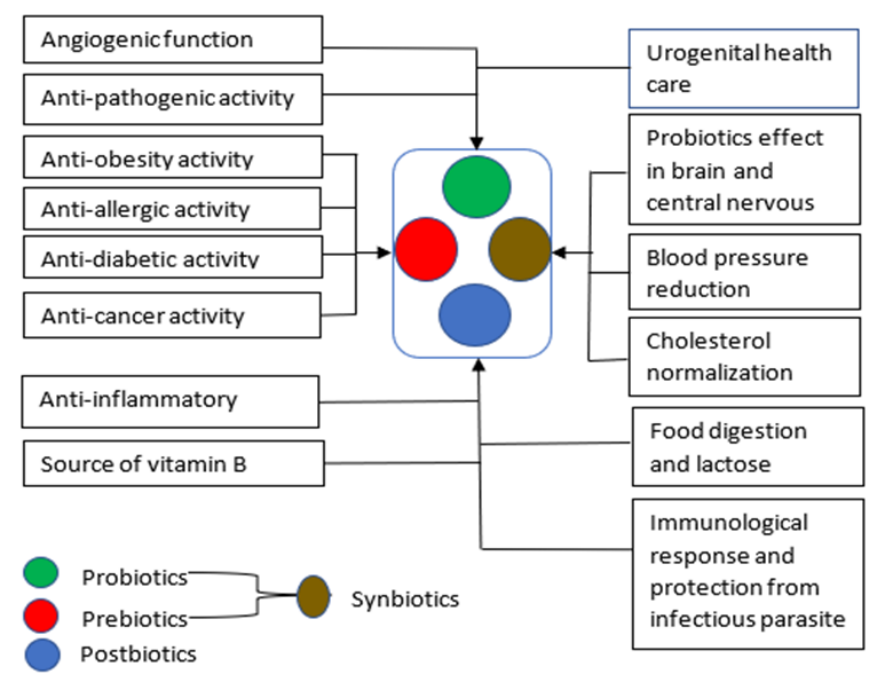

Figure 1. Synbiotic applications with their mode of action (George Kerry et al., 2018)

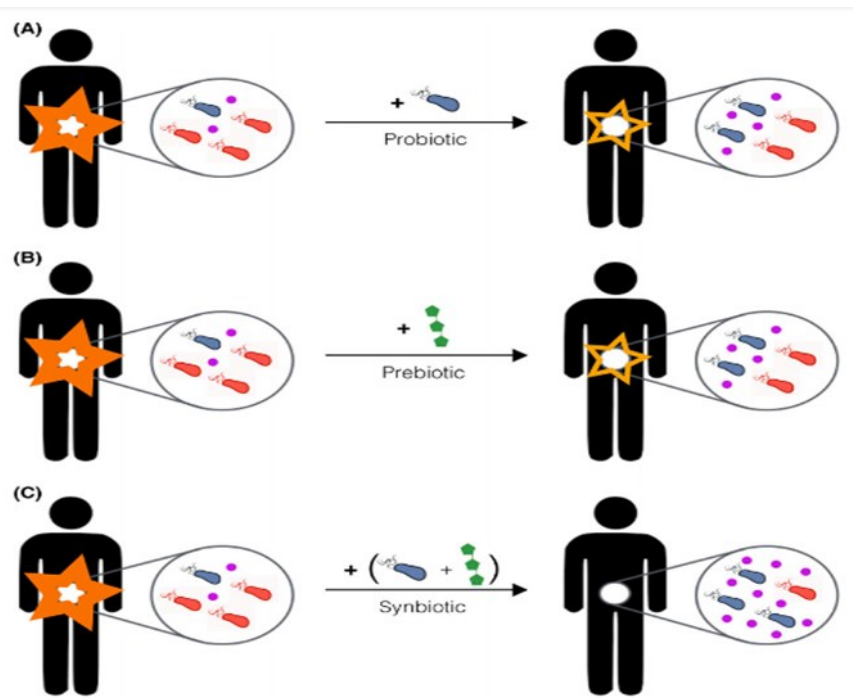

Figure 2. The synergistic effect of gut microorganisms (A) Administering of lactic acid (represented in purple color) producing probiotic (B) addition of prebiotic (C) synbiotic formulation (Gurry, 2017) 


\section{Probiotics}

The term probiotic was explained by a Russian scientist namely Elie Metchnikoff for the first time, by suggesting the possibility of replacing bad microbes with beneficial ones at the beginning of the 20th century (Khare et al., 2018). Metchnikoff also mentioned about the intake of fermented milk would "seed" the lactic acid bacteria and helps to reduce the outgrowth of proteolytic bacteria. Probiotic is live microorganisms that promote the intestinal microbial status and beneficially affect the host (Pandey et al., 2015). Food and Agriculture Organization (FAO) and the World Health Organization (WHO) (FAO/WHO, 2001), defined probiotics as "live microorganisms when administered in adequate amounts confer a health benefit on the host". The mostly used probiotics genus is Lactobacillus, Bifidobacterium, Saccharomyces, Enterococcus, Leuconostoc, and Bacillus (Khare et al., 2018). There are few characteristics of an ideal probiotic. First of all, the culture should be gram-positive, must express a positive effect on the host health, resistant to acid and bile salt, with a minimum colony-forming unit (CFU) of $30 \times 109$ per gram. Secondly, the culture should be strain-specific with longer survival rates and multiply rapidly in the digestive area. Lastly, they should be nontoxic to the host with the firm and faster adhesiveness ability of a microorganism (Khare et al., 2018).

\subsection{Mechanism of action of probiotics}

Probiotics exhibit a lot of advantageous effects on the human body. For instance, probiotics can develop the existing microbial status in the gut area and balance the functional activities between bacteria and pathogens of the organism (Ta, 2010). Furthermore, probiotics can reduce the growth activity of harmful bacteria such as Clostridium perfringens, Escherichia coli, Campylobacter jejuni, and Salmonella enteritidis efficiently (Markowiak and Ślizewska, 2017). The way of action of probiotic includes strong epithelial barriers, mucosal adhesiveness properties, the prohibition of pathogen adhesion, competitive exclusion of pathogens, and immune system regulation. The intestinal barrier is the key defence system for maintaining epithelial integrity to save the organism from unfavourable conditions. The factors responsible to disrupt the barrier function are peptides (antimicrobial), Immunoglobulin A $(\operatorname{IgA})$, and the epithelial junction adhesion while antigens from bacteria and food can influence the inflammation that may cause the intestinal disorders (Ohland et al., 2010). The mechanisms of probiotics to increase the function of the intestinal barrier still not identified clearly. Studies have revealed that promoting gene expression for tight junction signalling can be a probable mechanism to amplify the mucosal barrier unity
(Anderson et al., 2010). Moreover, probiotics may have the ability to block pathogens by adhering with epithelial cells which exerts a beneficial effect for immune modulation by triggering the signalling cascade. The release of many soluble compounds from epithelial cells may contribute to direct/indirect activation of immune cells to prevent contagious diseases and the inflammation of the alimentary tract (Oelschlaeger, 2010). Organic acids generated by probiotics namely acetic and lactic acid can exert strong inhibitory action towards Gram-negative bacteria. The abovementioned acids are thought to be as principle antimicrobial components to fight against pathogens (Makras et al., 2006). One Individual bacteria can decrease the activity of another species bacteria by subsequent mechanisms: formation of hostile microbial ecology, exclusion of attainable bacterial receptors, emission of antimicrobial components, and competitive reduction of necessary nutrients (Khare et al., 2018).

\subsection{Potential preventive and therapeutic role of probiotics}

Studies have revealed the promising effect of probiotics on the development of strong immunity, protection against disease caused by infections or allergic substances, improvement in total antioxidant capacity (TAC) and plasma total glutathione (GSH) level (Gourbeyre and Denery, 2011; Roshan et al., 2019). Figure 3 shows some properties of ideal probiotics (Khare et al., 2018). Different studies have been conducted to determine the possible therapeutic application for disease prevention such as insulin resistance syndrome, type 2 diabetes, obeseness, and non -alcohol hepatic steatosis of probiotic microorganisms (Markowiak and Ślizewska, 2017; George Kerry et al., 2018). Probiotic shows significant contributions in host metabolic processes, thus improve their health status by reducing the risk of metabolic diseases such as hypertension, obesity, cardiovascular diseases, arteriosclerosis, cancer and ageing. Probiotics are also responsible for qualitative alterations in intestinal mucus which prevent pathogen binding (Moayyedi et al., 2010; Roy and Kumar, 2019). Moreover, pomegranate byproduct increases the growth of probiotic bacteria such as Bifidobacteria and Lactobacilli have been confirmed to have potential anti-obese activity. Wang et al. (2019), studied the effects of probiotics in obese adults and reported that probiotics show beneficial effects on weight reduction with the changes in lipid profile and glucose metabolism. Another study suggested that probiotic diet play a preventive role in obesity establishment and reduce the risk of problems associated with obesity (Rouxinol-Dias et al., 2016). 


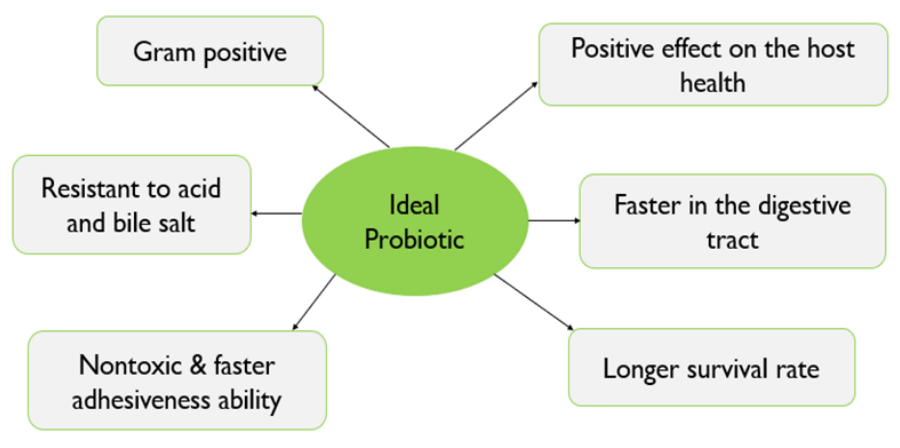

Figure 3. Properties of ideal probiotics (Khare et al., 2018)

\section{Prebiotics}

The term prebiotics was first commenced by Glenn Gibson and Marcel Roberfroid in 1995 and described as "a non-digestible food ingredient that beneficially affects the host by selectively stimulating the growth and/or activity of one or a limited number of bacteria in the colon, and thus improves host health" (Gibson and Roberfroid, 1995). Concerning the definition, only a limited number of carbohydrate groups can be categorized as prebiotics such as fructo-oligosaccharides (FOS), inulin, galacto-oligosaccharides (GOS). In 2008, the International Scientific Association of Probiotics and Prebiotics (ISAPP) defined "dietary prebiotics" as "a selectively fermented ingredient that results in specific changes in the composition and/or activity of the gastrointestinal microbiota, thus conferring benefit(s) upon host health". A compound must have the following criteria to be classified as prebiotic: resistant to acidic $\mathrm{pH}$ in the stomach, do not absorb in the gastrointestinal tract, can be fermented by intestinal microbes, can stimulate the growth/activity of the intestinal bacteria to improve host's health (Davani-Davari et al., 2019). The popular prebiotics is FOS, GOS, trans-galacto-oligosaccharides (TOS), Mannan-oligosaccharides (MOS), and inulin. Fruit by-products are a good source of carbohydrates with potential prebiotics (Ohshima et al., 2016). Moreover, prebiotics can be synthesized from starch or carbohydrates utilizing apposite enzymes. In recent years, the production of functional foods with prebiotic components has exhibited dominant features in food factories and promising market value for economic reasons and scientific evidence of its well-being. The result has shown that during bio-therapeutic formula preparation, appropriate microbial strains and prebiotic ingredients can improve the viability of probiotics in the target site (colon and small intestine) (Ohshima et al., 2016). Therefore, the increasing demand of health consciousness among consumers will offer remunerative opportunities for the prebiotic producer.

\subsection{Mechanism of action of prebiotics}

The intestinal microorganism works as a protector against very harmful bacteria by producing antimicrobial components and compete for epithelial attachment or nutrients (Schley and Field, 2002). By the fermentation, process prebiotics generates short-chain fatty acids (SCFAs) like propionic acid, lactic acid, and butyric acid which might have multiple advantages on human health (Davani-Davari et al., 2019). For instance, butyrate can influence the development of intestinal epithelial. These acids are highly digestible substrates for bacteria. Besides, they show advantageous effects on metabolic activity, $\mathrm{pH}$ value, increase the length and number of the intestinal and epithelial villus, respectively (Khare et al., 2018). Multiple surface determinants are displayed by prebiotics involving in the interaction process with intestinal epithelial cells (IECs) and mucus to prevent the adhesion of pathogenic bacteria (Khare et al., 2018). Mannan-oligosaccharides (MOS), act by agglutination via the collaboration process of mannose sensitive lectins that are found in the cell wall surface of particular gramnegative bacteria and restrain colonization of pathogens by the attachment of digestive tract site (Heinrichs et al., 2003). Another commonly used prebiotic namely inulin is not absorbed in the small intestine but can be fermented rapidly in other parts of the alimentary canal agitating proliferation of Lactobacillus and Bifidobacterium (Gibson and Roberfroid, 1995). A significant reduction of detrimental bacteria is also observed due to the changing effect of bifidogenic bacterial microbiota in the gut system. SCFAs produced by Bifidobacteria which can inhibit the proliferation and maintain low $\mathrm{pH}$ value with a concurrent hostile environment for pathogens. Furthermore, the proliferation caused by different species like E. coli, Clostridium perfirgensis and Salmonella can be repressed by several Bifidobacteria strains (Khare et al., 2018).

\subsection{Potential preventive and therapeutic role of prebiotics}

Parra-Matadamas et al., (2015) investigated the prebiotic activity of flour obtained from grapefruit, pear and pineapple peel in association with probiotic bacteria. Orange peel extract contains pectic oligosaccharides (POS) which expressed the prebiotic properties of increasing the number of Bifidobacteria and Eubacterium rectale with higher butyrate concentrations (Suárez et al., 2010). Hamzaha et al. (2018), reported that grape pomace extract shows a significant role in intestinal tract microbiota and improve gastrointestinal health with the presence of Lactobacillus acidophilus. Together with the polyphenol contents, grape seeds contain a particular number of oligosaccharides and prebiotic activity is the most well-demonstrated action of oligosaccharides (Bordiga et al., 2019). Agro-food byproduct offers a golden opportunity in nutraceuticals and 
value-added foods. XOS produced from these by-product presents the prebiotic efficiency on host health by optimising the activity in the colon, metabolic process and immunomodulatory function (Samanta et al., 2015). In addition, XOS can abate pro- carcinogenic enzymes, high $\mathrm{pH}$ value and nitrogenous waste. Resistant starch, which is unabsorbed in the gastrointestinal tract and oligosaccharides namely raffinose has been recognised as prebiotic carbohydrates that enhance the growth activity of good bacteria (Dwivedi et al., 2014).

\section{Conclusion}

Fruit processing by-products are effective and less expensive natural sources of bioactive compounds. These are typically considered useless but contain known bioactive components that exhibit significant antioxidant and synbiotic properties. Thus, it can be alternative sources of natural antioxidants and other bioactive compounds. The by-products of various fruits, i.e., mango, banana, watermelon, grape, pomegranate, papaya and apple are considered optimal sources of antioxidant compounds, prebiotics which can be utilised as a growth media for beneficial microbial strains. Several articles have been summarised in this review to provided concise information associated with the possible therapeutic application of antioxidants and synbiotics in human health disease. Individually selecting probiotics and prebiotics is a pre-requisite for synbiotic combination to maximise the synergic and beneficial effects. Antioxidants and prebiotics from by-products have multifactorial effects on the host health by improving the intestinal environment and metabolic process with negligible side effects. As a result, these can be used as less expensive but effective sources of healthcare supplements. This summery also illustrated the potential therapeutic applications including modes of action of bioactive compounds, which can be a useful guideline for future researchers. The present study recommends that further research should address toxicity and the effects of the long-term dietary intervention of synbiotics before clinical.

\section{Conflict of interest}

The authors declare they have no conflict of interests.

\section{Acknowledgments}

We would like to express our sincere thanks to School of Industrial Technology, Universiti Sains Malaysia which supported our project from its beginning. The financial support for the GA scheme from Universiti Sains Malaysia for Beauty Akter was gratefully acknowledged.

\section{References}

Al-Sayed, H.M.A. and Ahmed, A.R. (2013). Utilization of watermelon rinds and sharlyn melon peels as a natural source of dietary fiber and antioxidants in cake. Annals of Agricultural Sciences, 58(1), 83-95. https://doi.org/10.1016/j.aoas.2013.01.012

Anderson, R.C., Cookson, A.L., McNabb, W.C., Park, Z., McCann, M.J., Kelly, W.J. and Roy, N.C. (2010). Lactobacillus plantarum MB452 enhances the function of the intestinal barrier by increasing the expression levels of genes involved in tight junction formation. BMC Microbiology, 10, 316. https:// doi.org/10.1186/1471-2180-10-316

Bankar, A., Joshi, B., Kumar, A.R. and Zinjarde, S. (2010). Banana peel extract mediated synthesis of gold nanoparticles. Colloids and Surfaces B, Biointerfaces, 80(1), 45-50. https://doi.org/10.1016/ j.colsurfb.2010.05.029

Barbulova, A., Colucci, G. and Apone, F. (2015). New Trends in Cosmetics: By-Products of Plant Origin and Their Potential Use as Cosmetic Active Ingredients. Cosmetics, 2(2), 82-92. https:// doi.org/10.3390/cosmetics2020082

Bhargava, A. (2008). Food, Economics, and Health. New York, USA: Oxford University Press Inc. https:// doi.org/10.1093/ acprof:oso/9780199269143.001.0001

Bordiga, M., Meudec, E., Williams, P., Montella, R., Traviaglia, F., Arlorioa, M., Coïssona, J.D. and Doco, T. (2019). The impact of distillation process on the chemical composition and potential prebiotic activity of different oligosaccharidic fractions extracted from grape seeds. Food Chemistry, 285, 423-430.

https://doi.org/10.1016/

j.foodchem.2019.01.175

Davani-Davari, D., Negahdaripour, M., Karimzadeh, I., Seifan, M., Mohkam, M., Masoumi, S.J., Berenjian, A. and Ghasemi, Y. (2019). Prebiotics: Definition, Types, Sources, Mechanisms, and Clinical Applications. Foods (Basel, Switzerland), 8(3), 92. https://doi.org/10.3390/foods8030092

Department of Agriculture of Malaysia (2017). Statistik Tanaman Buah-Buahan. Retrieved from Department of Agriculture of Malaysia website: http:// www.doa.gov.my/index/resources/aktiviti_sumber/ sumber_awam/maklumat_pertanian/ perangkaan_tanaman/perangkaan_buah_2017.pdf

Dias, M., Caleja, C., Pereira, C., Calhelha, R.C., Kostic, M., Sokovic, M., Tavares, D., José Baraldi, I., Barros, L. and Ferreira, I.C.F.R. (2020). Chemical composition and bioactive properties of byproducts from two different kiwi varieties, Food Research 
International, 127, 108753. https://doi.org/10.1016/ j.foodres.2019.108753.

Diplock, A.T., Aggett, P.J., Ashwell, M., Bornet, F., Fern, E.B. and Roberfroid, M.B. (1999). Scientific concepts of functional foods in Europe: consensus document. British Journal of Nutrition, 81(4), S11S27. https://doi.org/10.1017/S0007114599000471

do Espírito Santo, A.P., Cartolano, N.S., Silva, T.F., Soares, F.A., Gioielli, L.A., Perego, P., Converti, A. and Oliveira, M.N. (2012). Fibers from fruit byproducts enhance probiotic viability and fatty acid profile and increase CLA content in yoghurts. International Journal of Food Microbiology, 154(3), 135-144.

j.ijfoodmicro.2011.12.025

Dwivedi, S., Sahrawat, K., Puppala, N. and Ortiz, R. (2014). Plant prebiotics and human health: Biotechnology to breed prebiotic-rich nutritious food crops. Electronic Journal of Biotechnology, 17(5), 238-245. https://doi.org/10.1016/j.ejbt.2014.07.004

Emylia, K., Dasuki, M. and Zainuddin, N.A.S.N. (2013). Preliminary Study on Antiproliferative Activity of Methanolic Extract of Nephelium lappaceum Peels towards Breast (MDA-MB-231), Cervical (HeLa) and Osteosarcoma (MG-63) Cancer Cell Lines. Health and the Environment Journal, 4(2), 66-79

FAO/WHO. (2001). Report of a Joint FAO/WHO Expert Consultation on Evaluation of Health and Nutritional Properties of Probiotics in Food including Powder Milk with Live Lactic Acid Bacteria. Retrieved from FAO/WHO website: http://www.fao.org/3/aa0512e.pdf

Frumento, D., do Espirito Santo, A.P., Aliakbarian, B., Casazza, A.A., Gallo, M., Converti, A. and Perego, P. (2013). Development of milk fermented with Lactobacillus acidophilus fortified with Vitis vinifera marc flour. Food Technology and Biotechnology, 51 (3), 370-375

George Kerry, R., Patra, J.K., Gouda, S., Park, Y., Shin, H.S. and Das, G. (2018). Benefaction of probiotics for human health: A review. Journal of Food and Drug Analysis, 26(3), 927-939. https:// doi.org/10.1016/j.jfda.2018.01.002

Gibson, G.R. and Roberfroid, M.B. (1995). Dietary modulation of the human colonic microbiota. The Journal of Nutrition, 125(6), 1401-12. https:// doi.org/10.1093/jn/125.6.1401

Goni, I. and Hervert-Hernandez, D. (2012). By-Products from Plant Foods are Sources of Dietary Fibre and Antioxidants. In Rasooli, I. (Ed.). Phytochemicals Bioactivities and Impact on Health, p. 95-116. Intech Open. https://doi.org/10.5772/27923
González-Montelongo, R., Lobo, M.G. and González, M. (2010). Antioxidant activity in banana peel extracts: testing extraction conditions and related bioactive compounds. Food Chemistry, 119(3), 1030-1039. https://doi.org/10.1016/j.foodchem.2009.08.012

Gourbeyre, P. and Denery, S.B.M. (2011). Probiotics, prebiotics, and synbiotics: impact on the gut immune system and allergic reactions. Journal of Leukocyte Biology, 89(5), 685-695. https://doi.org/10.1189/ jlb. 1109753

Grajek, W., Olejnik, A. and Sip, A. (2005). Probiotics, prebiotics and antioxidants as functional foods. Acta Biochimica Polonica, 52(3), 665-671. https:// doi.org/10.18388/abp.2005_3428

Gurry, T. (2017). Synbiotic approaches to human health and well-being. Microbial Biotechnology, 10(5), 1070-1073. https://doi.org/10.1111/17517915.12789

Hamzaha, N., Wan Ishaka, W.R. and Abdul Rahman, N. (2018). Nutritional and Pharmacological Properties of Agro-Industrial By-Products From Commonly Consumed Fruits. SDRP Journal of Food Science and Technology, 3(4), 396-416. https:// doi.org/10.25177/jfst.3.4.3

Hardia, S. and Iqbal, S. (2014). Production of the Best Natural Health Supplements Using Fruit Waste Materials. The International Journal of Innovative Research and Development, 3(5).

Heinrichs, A.J., Jones, C.M. and Heinrichs, B.S. (2003). Effects of mannan oligosaccharide or antibiotics in neonatal diets on health and growth of dairy calves. Journal of Dairy Science, 86(12), 4064-4069. https://doi.org/10.3168/jds.S0022-0302(03)74018-1

Hernández-Alcántara, A.M., Totosaus, A. and PérezChabela, M.L. (2016). Evaluation of Agro-Industrial Co-Products as Source of Bioactive Compounds: Fiber, Antioxidants and Prebiotic. Acta Universitatis Cibiniensis. Series E: Food Technology, 20(2), 3-16. https://doi.org/10.1515/aucft-2016-0011

Ibrahim, U.K., Kamarrudin, N., Suzihaque, M.U.H. and Hashib, S.A. (2017). Local Fruit Wastes as a Potential Source of Natural Antioxidant: An Overview. IOP Conference Series: Materials Science and Engineering, 206(1), 012040. https:// doi.org/10.1088/1757-899X/206/1/012040

Irfanoglu, Z., Baldos, U., Hertel, T. and van der Mensbrugghe, D. (2014). Impacts of Reducing Global Food Loss and Waste on Food Security, Trade, GHG Emissions and Land Use (Presented at the 17th Annual Conference on Global Economic Analysis. Dakar, Senegal: Purdue University,

Iriondo-DeHond, M., Miguel, E. and Del Castillo, M.D. 
(2018). Food by-products as Sustainable Ingredients for Innovative and Healthy Dairy Foods. Nutrients, 10(10), 1358. https://doi.org/10.3390/nu10101358

Issar, K., Sharma, P.C. and Gupta, A. (2016). Utilization of apple pomace in the preparation of fiber-enriched acidophilus yoghurt. Journal of Food Processing and Preservation, 41(4), e13098. https:// doi.org/10.1111/jfpp. 13098

Jahurul, M.H., Zaidul, I.S., Ghafoor, K., Al-Juhaimi, F.Y., Nyam, K.L., Norulaini, N.A., Sahena, F. and Mohd Omar, A.K. (2015). Mango (Mangifera indica L.) by-products and their valuable components: a review. Food Chemistry, 183, 173-180. https:// doi.org/ 10.1016/j.foodchem.2015.03.046

Joshi, V.K., Kumar, A. and Kumar, V. (2012). Antimicrobial, antioxidant and phyto-chemicals from fruit and vegetable wastes: a review. International Journal of Food and Fermentation Technology, 2, $123-36$.

Jridi, M., Souissi, N., Salem, M.B., Ayadi, M.A., Nasri, M. and Azabou, S. (2015). Tunisian date (Phoenix dactylifera L.) by-products: Characterization and potential effects on sensory, textural and antioxidant properties of dairy desserts. Food Chemistry, 188, 815. https://doi.org/10.1016/j.foodchem.2015.04.107

Karnopp, A.R., Oliveira, K.G., de Andrade, E.F., Postingher, B.M. and Granato, D. (2017). Optimization of an organic yogurt based on sensorial, nutritional, and functional perspectives. Food Chemistry, 233, 401-411. https:// doi.org/10.1016/j.foodchem.2017.04.112

Khaizill, E., Nik, A. and Mohd, D. (2013). Preliminary Study on Anti-proliferative Activity of Methanolic Extract of Nephelium lappaceum Peels towards Breast (MDA-MB-231), Cervical (HeLa) and Osteosarcoma (MG-63) Cancer Cell Lines. Health and the Environment Journal, 4(2), 66-79

Khare, A., Thorat, G., Bhimte, A. and Yadav, V. (2018). Mechanism of action of prebiotic and probiotic. Journal of Entomology and Zoology Studies, 6(4), 51 $-53$.

Koocheki, A., Razavi, S.M.A., Milani, E., Moghadam, T.M., Abedini, M., Alamatiyan, S. and Izadkhah, S. (2007). Physical properties of watermelon seed as a function of moisture content and variety. International Agrophysics Journal, 21(1), 349-359.

Makras, L., Triantafyllou, V., Fayol-Messaoudi, D., Adriany, T., Zoumpopoulou, G., Tsakalidou, E., Servin, A. and De Vuyst, L. (2006). Kinetic analysis of the antibacterial activity of probiotic lactobacilli towards Salmonella enterica serovar Typhimurium reveals a role for lactic acid and other inhibitory compounds. Research in Microbiology, 157(3), 241247. https://doi.org/10.1016/j.resmic.2005.09.002

Manigandan, T., Mangaiyarkarasi, S.P., Hemalatha, R., Hemalatha, V.T. and Murali, N.P. (2012). Probiotics, Prebiotics and Synbiotics - A Review. Biomedical and Pharmacology Journal, 5(2), 295-304.

Markowiak, P. and Ślizewska, K. (2017). Effects of probiotics, prebiotics, and synbiotics on human health. Nutrients, 9(9), 1021. https://doi.org/10.3390/ nu9091021

Ministry of Commerce and Industry Government of India. (2011). Major producing countries of grapes in world. Retrieved on July 20, 2019, from Agriculture and Processed Food Products Export Development website: http://agriexchange.apeda.gov.in/Market Profile/one/GRAPES.aspx\#

Moayyedi, P., Ford, A.C., Talley, N.J., Cremonini, F., Foxx-Orenstein, A.E., Brandt, L.J. and Quigley, E.M. (2010). The efficacy of probiotics in the treatment of irritable bowel syndrome: a systematic review. Gut, 59(3), 325-332. https://doi.org/10.1136/ gut.2008.167270

Nadeem, M., Mahud, A., Imran, M. and Khalique, A. (2014). Enhancement of the oxidative stability of whey butter through almond (Prunus dulcis) peel extract. Journal of Food Processing and Preservation, 39(6), 591-598. https:// doi.org/10.1111/jfpp.12265

Nadzirah, K.Z., Zainal, S., Noriham, A., Normah, I., Siti Roha A.M. and Nadya, H. (2013). Physico- chemical properties of pineapple variety n36 harvested and stored at different maturity stages. International Food Research Journal, 20(1), 225-231.

Oelschlaeger, T.A. (2010). Mechanisms of probiotic actions-A review. International Journal of Medical Microbiology, 300(1), 57-62. https:// doi.org/10.1016/j.ijmm.2009.08.005

Ohland, C.L. and Macnaughton, W.K. (2010). Probiotic bacteria and intestinal epithelial barrier function. American journal of physiology. Gastrointestinal and Liver Physiology, 298(6), G807-G819. https:// doi.org/10.1152/ajpgi.00243.2009

Ohshima, T., Kojima, Y., Seneviratne, C.J. and Maeda, N. (2016). Therapeutic application of synbiotics, a fusion of probiotics and prebiotics, and biogenics as a new concept for oral Candida infections: A mini review. Frontiers in Microbiology, 2016, 00010. https://doi.org/10.3389/fmicb.2016.00010

Ozcan, T., Yilmaz-Ersan, L., Akpinar-Bayizit, A. and Delikanli, B. (2016). Antioxidant properties of probiotic fermented milk supplemented with chestnut flour ( $C$ astanea sativa Mill). Journal of 
Food Processing and Preservation, 41(5), e13156. https://doi.org/10.1111/jfpp.13156

Pandey, K.R., Naik, S.R. and Vakil, B.V. (2015). Probiotics, prebiotics and synbiotics- a review. Journal of Food Science and Technology, 52(12), 7577-7587. https://doi.org/10.1007/s13197-0151921-1

Park, E.J., Zhao, Y.Z., An, R.B., Kim, Y.C. and Sohn, D.H. (2008). 1,2,3,4,6-penta-O-galloyl-beta-Dglucose from Galla Rhois protects primary rat hepatocytes from necrosis and apoptosis. Planta medica, 74(11), 1380-1383. https://doi.org/10.1055/ s-2008-1081300

Parra-Matadamas, A., Mayorga-Reyes, L. and PérezChabela, M.L. (2015). In vitro fermentation of agroindustrial by-products: Grapefruit albedo and peel, cactus pear peel and pineapple peel by lactic acid bacteria. International Food Research Journal, 22(2), 859-865.

Pathak, P.D., Mandavgane, S.A. and Kulkarni, B.D. (2018). Waste to Wealth: A Case Study of Papaya Peel. Waste and Biomass Valorization, 10, 17551766. https://doi.org/10.1007/s12649-017-0181-x

Patterson, E., Ryan, P.M., Cryan, J.F., Dinan, T.G., Ross, R.P., Fitzgerald, G.F. and Stanton, C. (2016). Gut microbiota, obesity and diabetes Postgraduate Medical Journal, 92(1087), 286-300.

Pyar, H., Liong, M.T. and Peh, K.K. (2014). Potentials of pineapple waste as growth medium for Lactobacillus species. International Journal of Pharmacy and Pharmaceutical Sciences, 6(1), 142145

Rice-Evans, C. (2001). Flavonoid Antioxidants. Current Medicinal Chemistry, 8(7), 797-807. https:// doi.org/10.2174/0929867013373011

Rimando, A.M. and Perkins-Veazie, P.M. (2005). Determination of citrulline in watermelon rind Journal of Chromatography. A, 1078(1-2), 196-200.

Roshan, H., Ghaedi, E., Rahmani, J., Barati, M., Najafi, M., Karimzedeh, M. and Nikpayam, O. (2019). Effects of probiotics and synbiotic supplementation on antioxidant status: A meta-analysis of randomized clinical trials. Clinical nutrition ESPEN, 30, 81-88. https://doi.org/10.1016/j.clnesp.2019.02.003

Rouxinol-Dias, A.L., Pinto, A.R., Janeiro, C., Rodrigues, D., Moreira, M., Dias, J. and Pereira, P. (2016). Probiotics for the control of obesity - Its effect on weight change. Porto Biomedical Journal, 1(1), 12 24. https://doi.org/10.1016/j.pbj.2016.03.005

Roy, P. and Kumar, V. (2019). Functional Food: Probiotic as Health Booster. Journal of Food, Nutrition and Population Health, 2(2), 10-12. https://doi.org/10.21767/2577-0586.100042

Sáez-Lara, M.J., Robles-Sanchez, C., Ruiz-Ojeda, F.J., Plaza-Diaz, J. and Gil, A. (2016). Effects of Probiotics and Synbiotics on Obesity, Insulin Resistance Syndrome, Type 2 Diabetes and NonAlcoholic Fatty Liver Disease: A Review of Human Clinical Trials. International Journal of Molecular Sciences, 17(6), 928. https://doi.org/10.3390/ ijms17060928

Sagar, N.A., Pareek, S., Sharma, S., Yahia, E.M. and Lobo, M.G. (2018). Fruit and Vegetable Waste: Bioactive Compounds, Their Extraction, and Possible Utilization. Comprehensive Reviews in Food Science and Food Safety, 17(3), 512-531. https://doi.org/10.1111/1541-4337.12330

Sah, B.N.P., Vasiljevic, T., McKechnie, S. and Donkor, O.N. (2016). Effect of pineapple waste powder on probiotic growth, antioxidant and antimutagenic activities of yogurt. Journal of Food Science and Technology, 53(3), 1698-1708. https:// doi.org/10.1007/s13197-015-2100-0

Samanta, A.K., Jayapal, N., Jayaram, C., Roy, S., Kolte, A.P., Senani, S. and Sridhar, M. (2015) Xylooligosaccharides as prebiotics from agricultural by-products: Production and applications. Bioactive Carbohydrates and Dietary Fibre, 5(1), 62-71. https://doi.org/10.1016/j.bcdf.2014.12.003

Schilderman, P.A.E.L., ten Vaarwerk, F.J., Lutgerink, J T., Van Der Wurff, A., ten Hoor, F. and Kleinjans, J.C.S. (1995). Induction of oxidative DNA damage and early lesions in rat gastro-intestinal epithelium in relation to prostaglandin $\mathrm{H}$ synthase-mediated metabolism of butylated hydroxyanisole. Food and Chemical Toxicology, 33(2), 99-109. https://doi.org/ https://doi.org/10.1016/0278-6915(94)00125-8

Schley, P.D. and Field, C.J. (2002). The immuneenhancing effects of dietary fibres and prebiotics. British Journal of Nutrition, 87(S2), S221-S230. https://doi.org/10.1079/bjn/2002541

Sergeev, I.N., Aljutaily, T., Walton, G. and Huarte, E. (2020). Effects of Synbiotic Supplement on Human Gut Microbiota, Body Composition and Weight Loss in Obesity. Nutrients, 12(1), 222. https:// doi.org/10.3390/nu12010222

Shan, B., Cai, Y.Z., Brooks, J.D. and Corke, H. (2011). Potential application of spice and herb extracts as natural preservatives in cheese. Journal of Medicinal Food, 14(3), 284-290. https://doi.org/10.1089/ jmf.2010.0009

Shklar, G. (1998). Mechanisms of cancer inhibition by anti-oxidant nutrients. Oral Oncology, 34(1), 24-29. https://doi.org/10.1016/s1368-8375(97)00060-2 
Suárez, B., Álvarez, Á.L., García, Y.D., Barrio, G., Lobo, A.P. and Parra, F. (2010). Phenolic profiles, antioxidant activity and in vitro antiviral properties of apple pomace. Food Chemistry, 120(1), 339-342. https://doi.org/10.1016/j.foodchem.2009.09.073

Ta, O. (2010). Mechanisms of probiotic actions - A review. International Journal of Medical Microbiology, 300(1), 57-62. DOI: 10.1016/ j.ijmm.2009.08.005.

Vafa, S., Haghighat, S., Janani, L., Totmaj, A.S., Navaei, M., Amirinejad, A., Emamat, H., Salehi, Z. and Zarrati, M. (2020). The effects of synbiotic supplementation on serum inflammatory markers and edema volume in breast cancer survivors with lymphedema. EXCLI Journal, 19, 1-15. https:// doi.org/10.17179/excli2019-1876

Wadhwa, M. (2016). Wastes to worth: value added products from fruit and vegetable wastes. $C A B$ Reviews: Perspectives in Agriculture, Veterinary Science, Nutrition and Natural Resources, 2015, 43. https://doi.org/10.1079/pavsnnr201510043

Wang, Z.B., Xin, S.S., Ding, L.N., Ding, W.Y., Hou, Y.L., Liu, C.Q. and Zhang, X.D. (2019). The Potential Role of Probiotics in Controlling Overweight/Obesity and Associated Metabolic Parameters in Adults: A Systematic Review and Meta-Analysis. Evidence-Based Complementary and Alternative Medicine, 2019, 3862971. https:// doi.org/10.1155/2019/3862971 